Que la dame Helisenne du Songe soit ou ne soit plus l'Hélisenne qui admirait son corps dans Les Angoysses, ou l'auteur qui a choisi la tradition onirique pour cette « représentation de l'Autre », elle reste un personnage invisible dont le conflit intérieur reste à résoudre. Il serait intéressant d'imaginer comment « Jeanne Flore », Marguerite de Navarre et quelques lectrices des années 1540 auraient interprété la « vehemente tristesse » et la « fascherie »d'Hélisenne lors de son réveil. Les lecteurs modernes seront sans doute loin de l'unanimité à ce sujet.

Peu d'entre nous seiziémistes étaient prêts à en affronter les difficultés, mais le « corpus hélisénien » est maintenant complet, grâce à Jean-Philippe Beaulieu et Diane Desrosiers-Bonin. Nous ne pouvons que recommander leur édition du Songe pour toute bibliothèque universitaire.

Les 222 notes (pour un texte de 90 pages) sont riches de renseignements, d'explications et de références souvent indispensables pour les citations d'interprétation ou d'identifications difficiles, et cela va sans dire, de complexités stylistiques. La Bibliographie (169-176) ne comprend que les livres et les articles cités dans le volume mais réfère le lecteur à une bibliographie de l'ensemble des textes d'Hélisenne de Crenne. Le Glossaire (177-181) est bref mais les notes le complètent efficacement. L'Index (183-188), intimidant par sa richesse, sera du plus grand aide pour tout travail de recherches sur Le Songe.

RÉGine REYNOLdS-CORNell, Agnes Scott College

\title{
Nicolas Ducimetière
}

Mignonne, allons voir ... Fleurons de la bibliothèque poétique Jean Paul

\section{Barbier-Mueller}

Genève-Paris : Musée Barbier-Mueller-Hazan, 2007, 538 p.

Les spécialistes de poésie française de la Renaissance connaissent tous les ouvrages anciens et rares que $M$. Jean Paul Barbier a accumulés depuis plusieurs décennies. Ils ont donné lieu à une formidable recension nourrie d'informations biographiques, historiques et littéraires qui a abouti à la publication en plusieurs tomes de $M a$ Bibliothèque poétique (Genève, Droz, 1990-...). Cette série figure dans toutes les bibliothèques publiques et personnelles car elle offre un catalogue de référence inégalé et une source d'informations nécessaire pour la poursuite des travaux universitaires, qu'ils soient littéraires ou bibliographiques.

Avec la parution d'une sélection des beaux livres du XVI ${ }^{\mathrm{e}}$ siècle composant la collection de M. Barbier, à Genève, le curieux et le chercheur disposent d'un outil 
supplémentaire. Car l'anthologie proposée par N. Ducimetière - catalogue établi à l'occasion d'une exposition itinérante, de Genève à Chantilly, en 2007 - présente de nouvelles notices savantes mettant en valeur des exemplaires déjà connus mais aussi des acquisitions récentes qui sont venues enrichir la collection du bibliophile genevois.

En huit sections, N. Ducimetière offre à la contemplation gourmande de ses lecteurs une guirlande de pièces exceptionnelles par leur rareté d'éditions et par la qualité de leur reliure. Dans cet ensemble, les éditions anciennes des plaquettes, recueils et collectives des Euvres de Pierre de Ronsard occupent une place de choix (p. 34-109). On y découvre ou redécouvre des textes depuis les débuts littéraires du poète (1549) jusqu'à ses derniers instants. Aucun des recueils importants de Ronsard ne semble manquer ici. Des Odes (1550) aux Euvres de 1587, en passant par les Amours (1552), la première collective des Euvres (1560), le Recueil des nouvelles poesies (1564) et La Franciade (1572), l'ensemble du corpus ronsardien est rassemblé, analysé et mis en valeur par un apparat critique succinct et parfaitement informé. Le catalogue permet aussi d'y découvrir des pièces d'exception, telles que quelques lettres manuscrites de Ronsard, servies par une reproduction photographique de grande qualité. N. Ducimetière fournit pour chaque notice de ces livres une information qui documente leur provenance, leur valeur historique et littéraire, ainsi qu'une orientation bibliographique précieuse. Le lecteur dispose ainsi d'un ouvrage érudit qui dépasse largement le cadre habituel offert par les catalogues d'exposition.

Outre Ronsard, ses compagnons de « La Pléiade » (J. Du Bellay, P. de Tyard, J.-A. de Baif, É. Jodelle, J. Dorat ... ), les poètes de la génération suivante (Jamyn, Pibrac), jusqu'au début du XVII e siècle, sont aussi bien servis. Leurs ouvrages, accompagnés d'un cortège de livres d'auteurs moins connus (G. Des Autels, J. Tahureau ... ), font l'objet de descriptions précises et riches, nourries de la lecture des travaux universitaires les plus actuels. Il serait vain de vouloir tous les citer tant la sélection présentée ici ne cesse de surprendre et d'éblouir.

On l'a compris, le travail éditorial réalisé par N. Ducimetière, heureux conservateur de la collection de M. Barbier, doit figurer dans toute bibliothèque d'amateur et de chercheur spécialisé. Dans ce trésor inestimable, chacun pourra puiser une source documentaire et d'inspiration nécessaire à l'exploration scientifique, qu'elle touche à l'histoire du livre ou à l'histoire littéraire.

FRANÇOIS ROUGET, Queen's University 